\title{
Evaluation of Desho Grass for Their Agronomic Performances and Nutritive Values in Highland and Midland Areas of Guji Zone, Southern Oromia, Ethiopia
}

\author{
Teshale Jabessa ${ }^{1,}$, , Ketema Bekele ${ }^{1}$, Zinash Amare ${ }^{2}$ \\ ${ }^{1}$ Bore Agricultural Research Center, Oromia Agricultural Research Institute, Bore, Ethiopia \\ ${ }^{2}$ Fiche Agricultural Research Center, Oromia Agricultural Research Institute, Bore, Ethiopia \\ Email address: \\ teshalejabessa@gmail.com (T. Jabessa) \\ ${ }^{*}$ Corresponding author
}

\section{To cite this article:}

Teshale Jabessa, Ketema Bekele, Zinash Amare. Evaluation of Desho Grass for Their Agronomic Performances and Nutritive Values in Highland and Midland Areas of Guji Zone, Southern Oromia, Ethiopia. Science Research. Vol. 9, No. 3, 2021, pp. 35-40. doi: $10.11648 /$ j.sr.20210903.11

Received: March 13, 2021; Accepted: June 2, 2021; Published: June 10, 2021

\begin{abstract}
The study was conducted with the objective to identify adaptability, high fresh biomass and dry matter yield of desho grass varieties. Four desho grass varieties; Kindo Kosha DZF No\# 591, Areka DZF No\# 590, Kulumsa DZF No \# 592 and Kindo Kosha DZF No\# 589 were evaluated in randomized complete block design (RCBD) with three replications. At highland area the revealed result that fresh biomass, leaf length per plant and plant height were significantly $(\mathrm{P}<0.05)$ differ among the treatments. The highest value of plant height was measured from Kindo Kosha DZF No\# $589(102.6 \mathrm{~cm})$ followed by Areka DZF No\# 590, Kulumsa DZF No \# $592(97.7 \mathrm{~cm})$ varieties, while the shortest plant height was recorded from Kindo Kosha DZF No\# 591 (91.2 cm) variety. The highest dry matter yield was obtained from Areka DZF No\# 590 (30.53t/ha), while the lowest dry matter yield was produced from Kindo Kosha DZF No\# 591 (24.8 t/ha). The highest survive rate was measured from Areka DZF No\# 590 (63.3\%) followed by Kindo Kosha DZF No\# 589 (61.3\%) varieties. Chemical composition showed that Areka DZF No\# 590 was highest in Dry matter (DM) (95.5\%) and the lowest dry matter (DM) was obtain from Kindo Kosha DZF No\# 591 (94.2\%) variety. At Midland area the revealed result that number of tiller per plant, number of leaf per plant, leaf length per plant, fresh biomass and plant height were significantly $(\mathrm{P}<0.05)$ differ among the treatments. The highest plant height was measured from Areka DZF No\# $590(108.6 \mathrm{~cm})$ followed by Kindo Kosha DZF No\# $589(107 \mathrm{~cm})$ while the lowest plant height was measured from Kindo Kosha DZF No\# $591(95.3 \mathrm{~cm})$ variety. The highest dry matter yield was measured from Areka DZF No\# 590 (27.13 t/ha) variety. The highest in Dry matter (DM) (95.02\%) and lowest in Acid detergent fiber (ADF) was measured from Areka DZF No\# 590 (43.8\%) varieties. The highest crude protein (CP) was measured from Kulumsa DZF No \# 592 (10.6\%) followed by Kindo Kosha DZF No\# 591 (9.8\%). The result implies that Kindo Kosha DZF No\# 589 and Areka DZF No\# 590 and Kindo Kosha DZF No\# 591 varieties were well performed in agronomic, yield and quality parameters. Thus it could be possible to conclude that the desho grass varieties should be recommended for improving the constraint of feed shortage in highland and midland of Guji zone and similar agro ecologies.
\end{abstract}

Keywords: Evaluation, Pennisetum Pedicellatum, Nutritive, Agronomic Performance

\section{Introduction}

Desho grass is one of the indigenous potential forage species which needed comprehensive research in Ethiopia. Desho grass (Pennisetum pedicellatum) is native to tropical countries including Ethiopia [5-6, 9].

In Ethiopia desho grass is known as a perennial plant originated in Southern Nations, Nationalities Peoples Regional State in a place called Chencha in 1991 [14].

Desho grass is a many-branched leafy grass growing up to $1 \mathrm{~m}$ high or more $[7,9]$.

The culms are erect and branching, and the leaves are 15$25 \mathrm{~cm}$ long and $4-10 \mathrm{~mm}$ wide, flat and glabrous. The spikelet's are $4 \mathrm{~mm}$ long, usually solitary [5, 7]. 
Desho grass is mainly found on disturbed land, road edges and on recent fallow lands, where annual rainfall range between $600 \mathrm{~mm}$ and $1500 \mathrm{~mm}$ with a rainy season of 4-6 months and average daily - temperatures of about $30-35^{\circ} \mathrm{C}$. Desho grass thrives on a wide range of soils (including degraded sandy or ferruginous soils) provided they are well drained. However, the grass is susceptible to water logging and frost but has some drought tolerance $[5,7]$.

Currently it is utilized as a means of soil conservation practices and animal feed in the highlands of Ethiopia [5, 15].

The grass is popular, drought resistant plant, used as feed for ruminants [6, 7]. It has the potential of meeting the challenges of feed scarcity since it provides more forage per unit area and ensures regular forage supply due to its multicut nature [5]. Desho grass is suitable for intensive management and performs well at an altitude ranging from 1500 to 2800 m.a.s.l [9]. Desho grass performs best at an altitude greater than $1700 \mathrm{~m}$ above sea level [14].

The provision of all the technical specifications for cultivation of desho grass is essential to improve grazing land management practices. Cuts of the grass are ideally planted in rows, spaced at $10 \mathrm{~cm}$ by $10 \mathrm{~cm}$, using a hand hoe [10]. This spacing gives each plant sufficient soil nutrients and access to sunlight to achieve optimal growth, while ensuring that the soil is completely covered by the grass once established.

It is recommended to plant other leguminous species alongside desho grass to promote biodiversity. Multipurpose shrubs/trees (Leucaena $s p$ and Sesbania $s p$.) can be planted approximately $5 \mathrm{~m}$ apart with no particular layout. Other legumes (alfalfa and clover) can be mixed with desho grass by broadcast throughout the plot [3].

Once planted, desho grass maintenance activities such as applying fertilizer, weeding and gap filling, are required to ensure proper establishment and persistency of desho grass [11].

Fertilizer should be applied throughout the plot one month after planting. It is recommended to use organic compost in the form of animal manure, leaf litter, wood ash, food scraps, and/or any other materials rich in biodegradable matters [3].

After 2 to 3 years, maintenance inputs decrease substantially or cease altogether as the grass cover closes up and the plot becomes a sustainable fodder source. Past interventions have shown that desho based grazing land management practices are best implemented when communal grazing land is re-distributed into small plots (less than 0.5 ha) that are convenient for individual use, development and management [3].

Desho grass has a crude protein content of $9.6 \%$ on DM basis at early stage and $1.6 \%$ at straw stage, respectively. The digestibility and voluntary intake decrease with increase in stage of maturity which indicates that the grass should be fed at early stage of maturity. Mature desho grass must be well supplemented with protein sources in order to sustain growth and/or milk production. Urea treatment may be a valuable option to improve its nutritive value (nitrogen content and digestibility) with the addition of adequate energy supplementation.

From animal feed resource point of view, desho grass is used in temporary pastures or in cut-and carry systems since it provides ample quantities of good quality green forage and stands several cuts a year. The grass is also useful for hay and silage preparation [5].

To improve availability of livestock feed in terms of quantity and quality, it is better to cultivate Desho grass forage that have better biomass yield and nutritional quality. Therefore, the objective of the present study was to evaluate the adaptability potential Good biomass yield, leaf to steam ratio and nutritional quality of desho grass varieties grown at high land and mid land parts of Guji zone.

\section{Materials and Methods}

\subsection{Description of the Study Area}

The experiment was carried out at Bore Agricultural Research Center, which is one of the recently established Research Centers of the Oromia Agricultural Research Institute (OARI) in Bore district, Guji Zone of Oromia. Bore district is located at $385 \mathrm{~km}$ to the south Oromia from Finfinne and $220 \mathrm{~km}$ from the Guji Zone capital city (Negele) with geographical location of 557'23" to 626'52" N latitudes and $3825^{\prime} 51^{\prime \prime}$ to 3856 '21" E longitudes, Southeastern Oromia. The annual rain fall is about $1400-1800 \mathrm{~mm}$ and the annual temperatures of the district ranged from 10.1 to $20 \mathrm{C}$. The major soil types of the site is mostly black soil. Bore Agricultural Research station is located at $7 \mathrm{~km}$ from Bore district which is geographically located at 624'37" N latitude and 3834'76" E longitudes. The research site represents highlands of Guji Zone with an altitude of 2736 m.a.s.l. receiving high rainfall characterized by bimodal distribution. The first rainy season extends from April to October and the second season starts late November and ends at the beginning of March and Adola District is located at distance of $470 \mathrm{~km}$ from Addis Ababa and $120 \mathrm{~km}$ from the Zonal capital city, Negele Borena. It is an area are a mixed farming and semi-nomadic economic activity takes place, which is the major livelihood of the local people. The total area of District is $1254.56 \mathrm{~km}^{2}$. The District is situated at

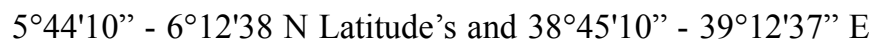
Longitudes. The District is characterized by three agroclimatic, namely highland (11\%), midland (29\%) and lowland $(60 \%)$. The major soil type of the district are nitosols (red basaltic soils) and orthic acrosols (Yazachew E. and Kasahun D. 2011).

\subsection{Experimental Treatments and Design}

The experiment was conducted using four varieties Kindo Kosha DZF No\# 591, Areka DZF No\# 590, Kulumsa DZF No \# 592 and Kindo Kosha DZF No\# 589.

The experiment was conducted in randomized complete block design (RCBD) with three replications. Splits of plant tiller were planting in rows spaced $50 \mathrm{~cm}, 10 \mathrm{~cm}$ between plants and $1 \mathrm{~m}, 1.5 \mathrm{~m}$ between plot and block respectively on plot size 
of $4 \mathrm{~m} \times 3 \mathrm{~m}\left(12 \mathrm{~m}^{2}\right)$. Splits of plant tillers \& fertilizer was applied and other agronomic crop protection practices was adopted uniformly as per recommendation for production.

\subsection{Data Collection}

All relevant data like days to vigor, plot cover, number of tiller per plants, number of leaf per plants, leaf length per plants, number of survive rates, plant heights, leaf to stem ratio, fresh biomass and dry matter yield and nutritive value were recorded.

\subsection{Chemical Analysis}

Samples of feeds were dried in an oven for $72 \mathrm{hr}$. at $65^{\circ} \mathrm{C}$ to determine the DM, Ash and $\mathrm{N}$ contents were determined according to the standard procedure of AOAC (1990). The ash content was determined by burning/igniting feed samples in a muffle furnace at $5500 \mathrm{C}$ and $\mathrm{N}$ content of feeds was determined according to Kejldhal procedure and the crude protein (CP) was calculated as $\mathrm{N}^{*} 6.25$. Neutral detergent fiber (NDF), acid detergent fiber (ADF) and acid detergent lignin (ADL) were analyzed according to the procedure of Van Soest and Robertson (1985). Hem-cellulose (HC) and cellulose $(\mathrm{C})$ contents were calculated as NDF minus ADF and $\mathrm{ADF}$ minus ADL, respectively.

\subsection{Statistical Analysis}

All collected data were analyzed using the general linear model procedure of SAS (SAS 2002) version 9.1. Mean were separated using least significant difference (LSD) at 5\% significant level. The statistical model for the analysis data was:

$$
Y i j k=\mu+A j+B i+e i j k
$$

Where; Yijk= response of variable under examination, $\mu=$ overall mean, $\mathrm{Aj}=$ the $\mathrm{jth}$ factor effect of treatment/ cultivar, $\mathrm{Bi}=$ the ith factor effect of block/ replication, eijk $=$ the random error.

\section{Results and Discussion}

\subsection{Yield and Yield Components}

Mean value of growth traits and phenology parameter of desho grass are show in (table) below.

Table 1. The mean value of traits of agronomic and yield component of desho grass at highland areas of Guji zone.

\begin{tabular}{|c|c|c|c|c|c|c|c|c|c|c|}
\hline \multirow{2}{*}{ Varieties } & \multicolumn{10}{|c|}{ Growth traits of parameters } \\
\hline & Pc\% & $\mathrm{Vg} \%$ & SR\% & NTPP & NLPP & LLPP & PH & LSR & FBMt- $^{1}$ & DMYt $^{1}$ \\
\hline Kindo Kosha DZF No\# 591 & $74 \mathrm{ab}$ & 74.8 & 58.6 & 137.9 & 11.14 & $37.6 b$ & $91.2 b$ & 0.76 & $36 b$ & 24.8 \\
\hline Areka DZF No\# 590 & $74 \mathrm{ab}$ & 78.4 & 63.3 & 145.7 & 13.77 & $45.2 \mathrm{a}$ & $97.7 \mathrm{ab}$ & 0.77 & $41.5 \mathrm{ab}$ & 30.5 \\
\hline Kindo Kosha DZF No\# 589 & $78.4 \mathrm{a}$ & 77.7 & 61.33 & 135.3 & 14.17 & $42.3 \mathrm{a}$ & $102.6 \mathrm{a}$ & 0.78 & $43.1 \mathrm{a}$ & 28.7 \\
\hline Mean & 73.3 & 76.5 & 57.5 & 141.1 & 12.85 & 41.9 & 97.2 & 0.73 & 39.9 & 27.8 \\
\hline $\mathrm{CV}$ & 6.2 & 10.3 & 25.7 & 5.6 & 14.4 & 4.1 & 4.4 & 17.5 & 7.2 & 11.4 \\
\hline
\end{tabular}

${ }^{a, b, c}$ Mean in a column within the same category having different superscripts differ significantly $(\mathrm{p}<0.05) \mathrm{PH}(\mathrm{cm})=$ plant height in centimeter, Pc=plot cover, $\mathrm{LSR}=$ leaf to steam ratio, $\mathrm{Vg}=$ vigor in percentage, $\mathrm{SR} \%=$ survive rate, NTPP=number of tiller per plants, NLPP $=\mathrm{Number}$ of leaf per plants, $\mathrm{LLPP}=\mathrm{Leaf}$ length per plants $\mathrm{FBMt}^{-1}=$ Fresh biomass tone per hectare, $\mathrm{DMYt}^{-1}=$ dry matter yield tone per hectare, $\mathrm{CV}=\mathrm{Coefficient}$ of variation, $\mathrm{LSD}=\mathrm{Least}$ significant difference, ${ }^{*}=$ significantly different, $* *=$ highly significant, $\mathrm{ns}=$ None significant different.

Table 2. The mean value of traits of agronomic and yield component of desho grass at midland areas of Guji zone.

\begin{tabular}{|c|c|c|c|c|c|c|c|c|c|c|}
\hline \multirow{2}{*}{ Varieties } & \multicolumn{10}{|c|}{ Growth traits of parameters } \\
\hline & Pc\% & $\mathrm{Vg} \%$ & SR\% & NTPP & NLPP & LLPP & PH & LSR & FBMt- $^{1}$ & DMYt- $^{1}$ \\
\hline Kindo Kosha DZF No\# 591 & 72.2 & 81.4 & 87.7 & $151.5 \mathrm{ab}$ & 10.3 & $40.3 b$ & $95.3 b$ & 0.46 & $39.6 a b$ & 26.01 \\
\hline Areka DZF No\# 590 & 71.0 & 79.2 & 95.7 & $134.2 \mathrm{~b}$ & $11.4 \mathrm{~b}$ & $44.7 \mathrm{ab}$ & $108.6 \mathrm{a}$ & 0.38 & $45 \mathrm{a}$ & 24.57 \\
\hline Kulumsa DZF No \# 592 & 63.6 & 77.4 & 76.6 & $168.2 \mathrm{a}$ & $10.5 b$ & $45.6 \mathrm{a}$ & $101.6 \mathrm{ab}$ & 0.39 & $37.9 \mathrm{~b}$ & 24.57 \\
\hline Kindo Kosha DZF No\# 589 & 71.1 & 79.5 & 92.4 & $156.8 \mathrm{ab}$ & $12.6 \mathrm{a}$ & $44 \mathrm{ab}$ & $107 \mathrm{a}$ & 0.45 & $44.9 \mathrm{a}$ & 26.13 \\
\hline Mean & 69.5 & 79.4 & 88.2 & 152.7 & 11.16 & 88.2 & 103.1 & 0.41 & 41.8 & 25.96 \\
\hline $\mathrm{CV}$ & 20.4 & 4.8 & 15 & 7.4 & 6.8 & 4.4 & 4.3 & 18.1 & 6.5 & 7.7 \\
\hline
\end{tabular}

${ }^{a, b, c}$ Mean in a column within the same category having different superscripts differ significantly $(\mathrm{p}<0.05) \mathrm{PH}(\mathrm{cm})=\mathrm{plant}$ height in centimeter, Pc $=$ plot cover, $\mathrm{LSR}=$ leaf to steam ratio, $\mathrm{Vg}=$ vigor in percentage, $\mathrm{SR} \%=$ survive rate, $\mathrm{NTPP}=$ number of tiller per plants, NLPP $=\mathrm{Number}$ of leaf per plants, LLPP $=\mathrm{Leaf}$ length per plants $\mathrm{FBMt}^{-1}=$ Fresh biomass tone per hectare, $\mathrm{DMYt}^{-1}=$ dry matter yield tone per hectare, $\mathrm{CV}=\mathrm{Coefficient}$ of variation, $\mathrm{LSD}=\mathrm{Least}$ significant difference, ${ }^{*}=$ significantly different, $* *=$ highly significant, $\mathrm{ns}=$ None significant different.

The analyzed result show that plant height, plot cover and fresh biomass was significantly $(\mathrm{P}<0.05)$ different among the treatments and leaf length per plant was highly significant at $(\mathrm{p}<0.01)$. As General, Desho grass were more fresh biomass and plant heights at midland agro-ecology due to fluctuation of temperature. The highest plant height were measured from Areka DZF No\# $590(108.6 \mathrm{~cm})$ followed by Kindo Kosha
DZF No\# $589(107 \mathrm{~cm})$ varieties at midland area. The highest value of dry matter yield were measured from Areka DZF No\# 590 (30.5 t/ha) followed by Kindo Kosha DZF No\# 589 $(28.73 \mathrm{t} / \mathrm{ha})$ at highland area. This is due to heavily rain for long time at highland. Desho grass variety was more survive at midland agro-ecology.

On the other hands, number of tiller per plants, number of 
leaf per plant, leaf length per plant and fresh biomass were show significant $(\mathrm{P}<0.05)$ different between treatments at midland area. However, numerically the highest biomass during conducted experiment were recorded at Adola sub site. Due to more survive number of plant at midland area.

The mean value of plot cover performance of Desho grass adaptation considered in this experiment were promised for future works (73.3\%) and even though the mean value between desho grasses was indicated significance difference $(\mathrm{P}<0.05)$ on plot cover at highland area. The higher plot cover were produced from Kindo Kosha DZF No\# 589 (78.4\%). This result is lower than result reported by [12].

Plant vigor percent was not shown significant difference (P>0.05) at both agro-ecology. However, numerically it had different values. The highest plant vigor percent was recorded from Kindo Kosha DZF No\# 591 (81.4\%) and Areka-DZF \# 590 (78.4\%) of Desho grass. This finding was not comparable with [12] 96.3\% for Areka-DZF \# 590 Desho grass lines plot cover percent in Southern, Ethiopia.

\subsection{Plant Height (cm)}

For plant height determination, mean height of five randomly selected plants were recorded for each plots of trials. Plant height was significantly differ $(\mathrm{P}<0.05)$ for both location at forage harvesting stage. The highest mean value of plant height was measured from Areka DZF No\# 590 (108.6cm), followed by Kindo Kosha DZF No\# 589 (107 $\mathrm{cm})$ varieties at midland area. This difference might be due to soil types and harvesting at different dates. This result higher than the result reported by [2] $(39.4 \mathrm{~cm})$ under irrigation at Northern Ethiopia.

The lowest plant height was recorded from Kindo Kosha DZF No\# $591(91.2 \mathrm{~cm})$ at highland area. This is due to fluctuation of temperature ad soil types. This result is higher than result reported by [8].

\subsection{Fresh Biomass Yield t/ha}

The fresh biomass weight of the cut biomass was recorded just after mowing using field balance. Then, subsample of
$300 \mathrm{~g}$ was taken and dried in air draft oven at $65^{\circ} \mathrm{C}$ for 72 hours to determine herbage dry matter yield (DMY). The mean average of biomass yield, at study area were show significant $(\mathrm{P}<0.05)$ different between treatments at both agro-ecology's.

The highest mean value of biomass was obtain from Areka DZF No\# 590 (45 t/ha) followed by Kindo Kosha DZF No\# 589 (44.9 t/ha). This result is lower than result reported by [8].

\subsection{Dry Matter Yield t/ha}

The highest mean value of herbage dry matter yield (DMY) was measured from Areka DZF No\# 590 (30.5t/ha) followed Kindo Kosha DZF No\# 589 (28.7t/ha) at highland agro-ecology area. This is due to more soil moisture content. The lowest dry matter yield was measured from Areka DZF No\# 590 and Kulumsa DZF No \# 592 (24.57t/ha). This is higher than the result reported by [4].

\subsection{Survive Rate (\%)}

The analysis variance of survive rate was not shown statistically significance difference $(\mathrm{P}>0.05)$ between two agro-ecology. The highest mean value of survive rate (SR) was measured from midland area. This due to soil types and highland area of Guji zone known as heavy rain in case of that on planting time some of tillers were didn't survive. The highest mean value was recorded from Areka DZF No\# 590 (95.7\%) followed by Kindo Kosha DZF No\# 591 (87.7\%) varieties.

\subsection{Leaf to Steam Ratio}

The analysis variance of leaf to stem ratio were not shown statistically significance difference $(\mathrm{P}>0.05)$ between two agro-ecology. More leaf to stem ratio were recorded at highland area. This is due to shuttering of leaf at midland area with fluctuation of temperature. The range leaf to stem ratio recorded were $(0.66-0.78)$. This result is higher than result reported by [12].

Table 3. Mean chemical composition of desho grass varieties at highland area.

\begin{tabular}{|c|c|c|c|c|c|c|}
\hline Varieties & $D M$ & TASH & $\boldsymbol{C P}$ & $N D F$ & $A D F$ & $A D L$ \\
\hline Kindo Kosha DZF No\# 591 & 94.2 & 12.5 & 17.07 & 72.6 & 42.2 & 12.03 \\
\hline Areka DZF No\# 590 & 95.5 & 13.2 & 17.2 & 71.6 & 47.7 & 6.98 \\
\hline Kulumsa DZF No \# 592 & 95.4 & 12.4 & 10.8 & 65.9 & 48.13 & 6.47 \\
\hline Kindo Kosha DZF No\# 589 & 94.5 & 14.7 & 10.21 & 70.3 & 46.5 & 9.5 \\
\hline
\end{tabular}

$\mathrm{DM}=$ dry matter, $\mathrm{TASH}=$ total ash, $\mathrm{NDF}=$ neutral detergent fiber, $\mathrm{ADF}=$ acid detergent fiber, $\mathrm{ADL}=$ acid detergent lignin, $\mathrm{CP}=\mathrm{crude}$ protein

Table 4. Mean chemical composition of desho grass varieties at midland area.

\begin{tabular}{llllll}
\hline Varieties & DM & TASH & CP & NDF & ADF \\
\hline Kindo Kosha DZF No\# 591 & 94.7 & 19.5 & 9.8 & 70.3 & 46.8 \\
Areka DZF No\# 590 & 95.02 & 17.6 & 8.8 & 66 & 43.8 \\
Kulumsa DZF No \# 592 & 92.5 & 15.3 & 10.6 & 66.9 & 10.09 \\
Kindo Kosha DZF No\# 589 & 94.02 & 19.7 & 8.84 & 69.4 & 26.7 \\
\hline
\end{tabular}

$\mathrm{DM}=$ dry matter, $\mathrm{TASH}=$ total ash, $\mathrm{NDF}=$ neutral detergent fiber, $\mathrm{ADF}=$ acid detergent fiber, $\mathrm{ADL}=$ acid detergent lignin, $\mathrm{CP}=\mathrm{crude}$ protein 


\subsection{Nutritive Value at Forage Harvesting Stage}

The chemical compositions of tested varieties are presented in Tables 3 and 4. The findings from this study revealed that Kindo Kisha-DZF\#589 variety had higher ash content than others at highland area. However, the ArekaDZF\#590 variety had higher CP and higher DM followed by Kindo Kosha DZF No\# 591 and Kindo Kisha-DZF\#589 had gave lowest $\mathrm{CP}$ contents. The similarity in crude protein and DM for all tested varieties is due to similarity in genetic make-up of varieties to accumulate similar nitrogen contents in a given environments. The result obtained from our study on CP values for all tested varieties were higher than previously reported values by (Denbela et al, 2020) which ranges from 6.93-9.38\% under different agroecologies.

The NDF and ADF are frequently used as standard for forage quality testing. The NDF approximates the total cell wall constituents and is used to predict intake potential in livestock and whereas, ADF primarily represents cellulose and lignin and is often used to calculate digestibility of feeds by [13]. The value obtained from our study for NDF was lower than previously reported values which ranged 72.78 $77.68 \%$ by $[1]$.

Moreover, at midland area for all tested varieties ash content is higher than highland area. This is due to soil types. From desho varieties (Table 3) Areka DZF No\# 590 variety was higher in DM, less in Acid detergent lignin (ADL) and NDF contents.

\section{Conclusions and Recommendation}

The result implies that Kindo Kosha DZF No\# 589 and Areka DZF No\# 590 for midland areas and Kindo Kosha DZF No\# 591 and Areka DZF No\# 590 for highland areas desho varieties were well adapted and being productive regarding the plant height, biomass yield and dry matter yield of desho grass which is hopeful to fill the gap of low quality and quantity ruminant feed supply of the community.

In current study Areka DZF No\# 590 varieties more survive and gave good yield components at both study areas. In addition the nutritional values (chemical composition) were promising particularly the dry matter (DM) and Organic Matter (OM) and less in ADFcontent in Areka DZF No\# 590. Thus it could be possible to conclude that the desho grass varieties especially Areka DZF No\# 590, Kindo Kosha DZF No\# 589 and Kindo Kosha DZF No\# 591 used as a protein supplement for highland and midland of Guji, which were suffering from poor quality roughage and low protein and digestible crop residues which were the major livestock feed sources particularly in Guji.

Based on its adaptability, plant height, biomass yield and dry matter yield, good DM and OM Areka DZF No\# 590, Kindo Kosha DZF No\# 589 and Kindo Kosha DZF No\# 591 is recommended for further promotion in the highland and midland of East Guji zone.

\section{Acknowledgements}

The authors are grateful to the Oromia Agricultural Research Institute (IQQO) for financial support to implement the study. The animal nutrition laboratory workers of Debre zeit were also acknowledged for their support in the chemical analysis of the feed samples.

\section{References}

[1] Bimrew A (2016). Evaluation of the Agronomic, Utilization, Nutritive and Feeding Value of Desho Grass (Pennisetum Pedicellatum). PhD. Dissertation, Jimma University, Ethiopia.

[2] Bimrew Asmare, Solomon Demeke, Taye Tolemariam, Firew Tegegne, Aynalem Haile et al. (2017) Effects of altitude and harvesting dates on morphological characteristics, yield and nutritive value of desho grass (Pennisetum pedicellatum Trin). in Ethiopia, Agriculture and Natural Resources 51: 148-153.

[3] Danano, D., 2007. Improved grazing land management in Ethiopia. In H. Liniger, \& W. Critchley (Eds), Where the land is greener (pp. 313-316). Bern, Switzerland: WOCAT.

[4] Denbela H, Berako B, Sintayehu K. Evaluation of Desho (Pennisetum pedicellatum) Grass Varieties for Dry Matter Yield and Chemical Composition in South Omo Zone, South Western Ethiopia. Agri Res \& Tech: Open Access J. 2020; 25 (2): 556294.

[5] Ecocrop, 2010. Ecocrop database. FAO. http://ecocrop.fao.org/ecocrop/srven/home. (Accessed 02 February 2015).

[6] EPPO (European and Mediterranean Plant Protection Organization), 2014. PQR database. Paris, France: European and Mediterranean Plant Protection Organization. http://www.eppo.int/DATABASES/pqr/pqr.htm (accessed on 29 July, 2015).

[7] FAO (Food and Agriculture Organization of the United Nations). 2010. Grassland Index. A searchable catalogue of grass and forage legumes Food and Agriculture Organization of the United Nations, Rome, Italy.

[8] Gadisa et al. (2019). Evaluation of Desho Grass (Pennisetum pedicellatum Trin) lines for their adaptability at Mechara Research Station, Eastern Oromia, and Ethiopia.

[9] Leta Gerba, Duncan, A., Asebe Abdena, 2013. Desho grass (Pennisetum pedicellatum) for livestock feed, grazing land and soil and water management on small-scale farms. ILRI, Nairobi, Kenya 2 pp.

[10] Smith, G., 2010. Ethiopia: Local solutions to a global problem. (Available

http://www.newag.info/en/focus/focusItem.php?a=1784)

(Accessed on 03 April, 2015).

[11] Solomon Gizaw, Azage Tegegne, Berhanu Gebremedhin and Dirk Hoekstra. 2010. Sheep and goat production and marketing systems in Ethiopia: Characteristics and strategies for 87 improvement. IPMS (Improving Productivity and Market Success) of Ethiopian Farmers Project Working Paper 23. ILRI (International Livestock Research Institute), Nairobi, Kenya. 58 pp. 
[12] Tekalegn Yirgu, Solomon Mengistu, Edao Shanku and Fromsa Ijara (2017). Desho Grass (Pennisetum. pedicellatum) Lines Evaluation for Herbage Yield and Quality under Irrigation at Wondogenet. American Eurasian Journal of Agricultural and Environmental Science 17 (5): 427-431.

[13] Van Soest PJ (1994) Nutritional ecology of ruminants. 2nd edition. Cornell university press, London USA pp: 476.

[14] Welle, S., Chantawarangul, K., Nontananandh, S. and
Jantawat, S., 2006. Effectiveness of grass strips as barriers against runoff and soil loss in Jijiga area, northern part of Somalia region, Ethiopia. Kasetsart Journal: Natural Science 40: 549-558.

[15] Yakob, G., Gebremicheal, A., Aklilu, A. and Melaku, E., 2015 Participatory Evaluation of Different Multipurpose Grass Species for Graded Soil Bund Stabilization in Gimbo District, South West Ethiopia. Open Access Library Journal, 2: e1627. http://dx.doi.org/10.4236/oalib.1101627. 